\title{
STUDY ON SHEAR CONNECTION OF BRIDGE STEEL TRUSS AND CONCRETE SLAB DECK
}

\author{
Josef MACHACEK, Martin CHARVAT \\ Department of Steel and Timber Structures, Faculty of Civil Engineering, Czech Technical University in Prague, \\ Thakurova 7, 16629 Prague, Czech Republic
}

Received 28 May 2014; accepted 23 Jul 2014

\begin{abstract}
Longitudinal shear flow in the connection of a bridge steel truss upper chord and a concrete bridge slab is studied both in elastic and plastic stages of loading up to the shear connection collapse. First the distribution of the shear flow with an increasing level of loading is shown as resulted from 3D MNA (materially nonlinear analysis) using ANSYS software package and a former experimental verification. Nevertheless, the flow peaks in elastic stages above truss nodes due to local transfer of forces are crucial for design of the shear connection in bridges. Therefore a simple approximate 2D elastic frame modelling was suggested for subsequent extensive parametric studies. The study covers various loadings including the design loading of bridges and demonstrates importance of rigidity of the shear connection, rigidity of an upper steel truss chord and rigidity of a concrete deck. Temperature effects and a creep of concrete are also studied. The substantial part of the study deals also with concentration of shear connectors in the area of steel truss nodes and influence of the connector densification on distribution of the longitudinal shear along an interface of the steel truss chord and the concrete deck. Eurocode 4 approach and quest to find an optimum design of the shear connection in composite bridge trusses are discussed. Finally the resulting recommendations for a practical design are presented.
\end{abstract}

Keywords: bridge, concrete deck, longitudinal shear, shear connection, steel and concrete composite, steel truss.

\section{Introduction}

Composite steel and concrete bridges of medium spans with steel part constructed as a truss proved to be both economic and aesthetic. For example, in the Czech Republic only, twelve such bridges with spans between 21 and $63 \mathrm{~m}$ were completed during last two decades, Figure 1. Experimental and theoretical investigation of composite trusses during last decades is adequately described (Viest et al. 1997; Machacek, Cudejko 2009, 2011; Stadler, Mayrhofer 2010; Machacek, Charvat 2013) and therefore attention is given to research concerning longitudinal shear along the steel truss and a concrete slab only.

In the ninetieth the comprehensive research relating to composite floor trusses (Skidmore 1992) resulted in design recommendations showing a wide range of relevant design aspects. Concerning design of the shear connection between a steel truss and a concrete slab the common plastic redistribution as in standard plate girders was suggested, provided the shear connectors were sufficiently ductile.

Such redistribution however, can not be applied for the elastic behaviour of the shear connection, where the highly non-uniform distribution of longitudinal shear is caused by transmitting forces predominantly from truss nodes to a concrete slab. The elastic distribution of the longitudinal shear due to local effect of a concentrated longitudinal force introduced into concrete slab of a composite continuous girder due to prestressing was investigated in the late ninetieth (Johnson 1997; Johnson, Ivanov 2001). The simplified results were also suggested for application in composite trusses and introduced into Eurocode 4 (EN 1994-2 (2005), described however
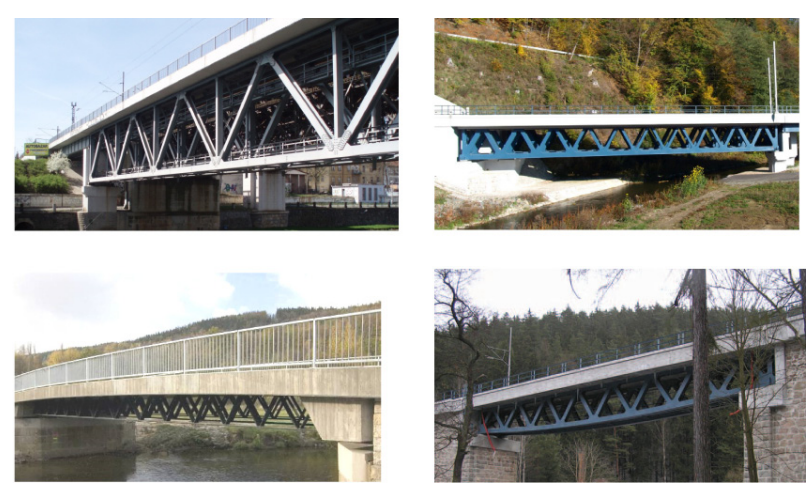

Fig. 1. Examples of recent motorway and railway composite truss bridges

Corresponding author: Josef Machacek

E-mail: machacek@fsv.cvut.cz 
in ENV 1994-2 in more details). The significant peaks of the longitudinal shear above truss nodes in elastic regions are obvious. The elastic design of the longitudinal shear is required for bridges (according to Eurocode 4 (EN 1994-2 2005)) both in serviceability and ultimate limit states incl. fatigue, tolerating $10 \%$ plastic redistribution in a given segment), in case of rigid shear connectors with respect to their limited deformation capacity and also always necessary for class 3 and 4 cross sections (determined according to Eurocode 4 (EN 1994-2)). Designers of bridges commonly use shear (vertical) force to calculate longitudinal shear, to which roughly add local effects due to differences of chord forces in truss nodes along an estimated length.

Recently new important studies concerning relevant parameters of steel truss chords, concrete slabs and shear connection in composite truss bridges were published (Bouchair et al. 2012; Bujnak et al. 2013). Other papers substantial for the following studies cover behaviour of shear connectors (Leon 2005; Mirza, Uy 2010; Faggiano et al. 2009), complete composite trusses (Marcinkowski, Berkowski 1997; Mujagic et al. 2010; Jung et al. 2010) and various design aspects (Kravanja, Silih 2003; Szmigiera 2007; Yatim et al. 2013).

Former investigation of the authors in this field started with experimental investigation of two identical floor truss girders with $6 \mathrm{~m}$ span and using perforated shear connectors providing "full" shear connection (see Fig. 2). The test results of both trusses together with common analytical calculation (as for plated beams) providing elastic $\left(F_{e l}\right)$ and plastic $\left(F_{p l}\right)$ capacities taking into account real geometrical and material characteristics and full composite action according to Eurocode 4 (EN 1994-1-1 2004) are presented in Figure 3.

It is evident that the tests justified common simple calculations for floor composite trusses.

Subsequently the more precise numerical 3D MNA (materially nonlinear analysis) using ANSYS software package was proposed (Machacek, Cudejko 2009, 2011), clarifying the entire process of longitudinal shear distribution along an interface between steel and concrete parts under both elastic and plastic behaviour. For central deflection and end slip see Figures 3 and 4.

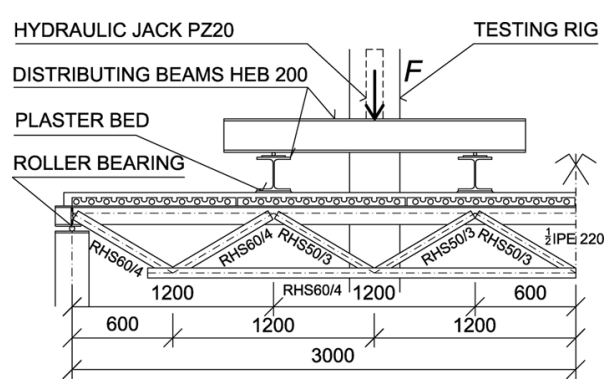

Fig. 2. Geometry of composite truss models and arrangement of loading. Concrete slab $1500 \times 80[\mathrm{~mm}]$

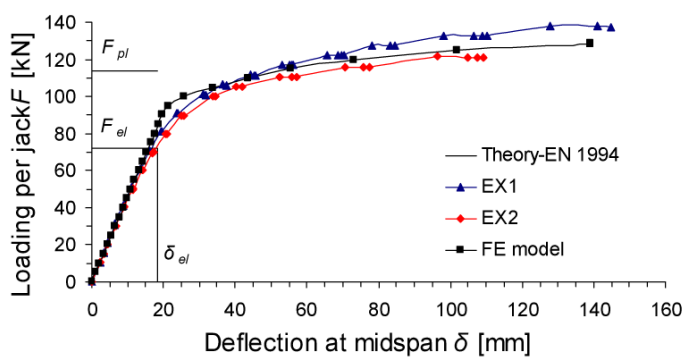

Fig. 3. Comparison of simple Eurocode 4 (EN 1994-1-1 2004) values with results of both tests and numerical 3D MNA (FE model)

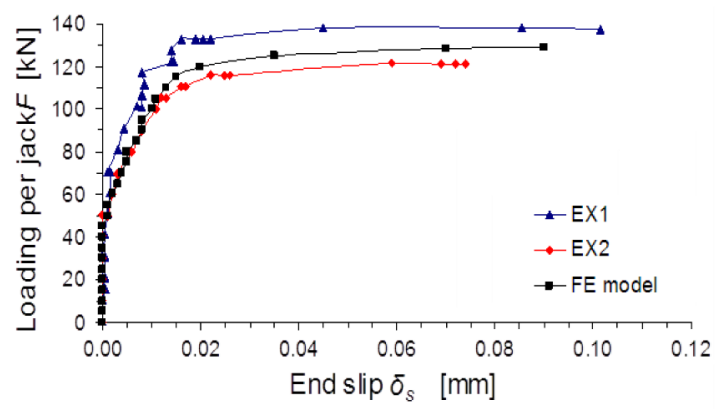

Fig. 4. Comparison of tests and numerical 3D MNA for end slip

The numerical model is very demanding but provided excellent agreement with tests results up to the collapse (Fig. 5) and may serve as a benchmark.

Nevertheless, detailed investigations of elastic distribution of the shear flow in the shear connection between a bridge steel truss and a concrete slab require vast parametric studies for which simplified 2D LA (linear elastic analysis) was proposed, verified and used.

The present paper i) explains the simplified 2D LA model, ii) presents results of wide parametric studies concerning various entry data, iii) clears up the distribution of longitudinal shear in bridges due to temperature effects, creep and shrinkage, iv) summarizes the results and provides substantial recommendations for a practical design.

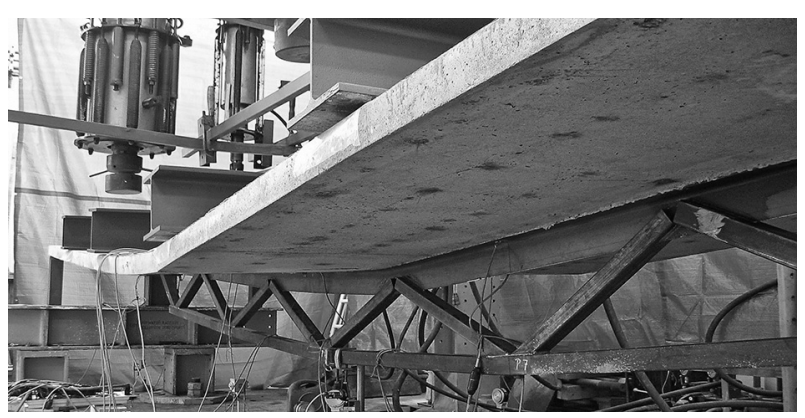

Fig. 5. The plastic collapse in laboratory 


\section{2D LA numerical model}

Instead of using rather demanding 3D MNA (materially non-linear analysis) mentioned above, the simplified 2D LA (linear elastic analysis) seems to be appropriate for studies in an elastic region.

Common SCIA Engineer software using simple 2D frame modelling was employed. The shear connectors were modelled as cantilevers sticking out from a member representing steel truss chord and pin connected at mid-plane of concrete slab substituted by a concrete strut (neglecting slab tension zone as recommended by Eurocode 4 (EN 1994-1-1 2004) for a shear connection analysis).

The verification of such simplification was studied for the first bridge shown in photos of Figure 1 with geometry according to Figure 6.

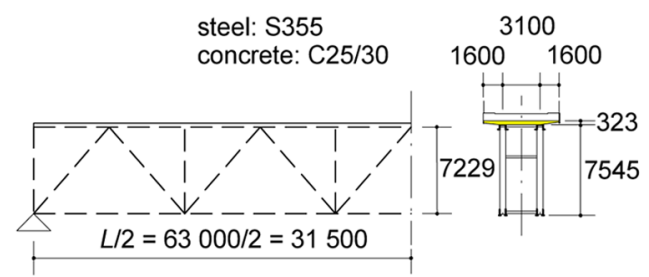

Fig. 6. The bridge geometry

The linear parts of stress-strain relationships for both steel and concrete (Young's modulus $E=210 \mathrm{GPa}$, $E_{\mathrm{cm}}=30.5 \mathrm{GPa}$ ) were introduced. The upper steel truss chord was formed as $\Pi$ (double web) profile and the shear connection provided by four parallel rows of welded studs 19/200 [mm] in $400 \mathrm{~mm}$ spacing. The non-linear behaviour of the connection (Oehlers, Coughlan 1986) was linearized and only the first linear part representing the 4 parallel studs introduced according to Figure 7 in the analyses.

The connection in this case was modelled as circular cantilever bars in spacing of $400 \mathrm{~mm}$, Figure 8 . The diameter of the bars follows from formula:

$$
D=\sqrt[4]{\frac{64 P \ell^{3}}{3 \pi E \delta}},
$$

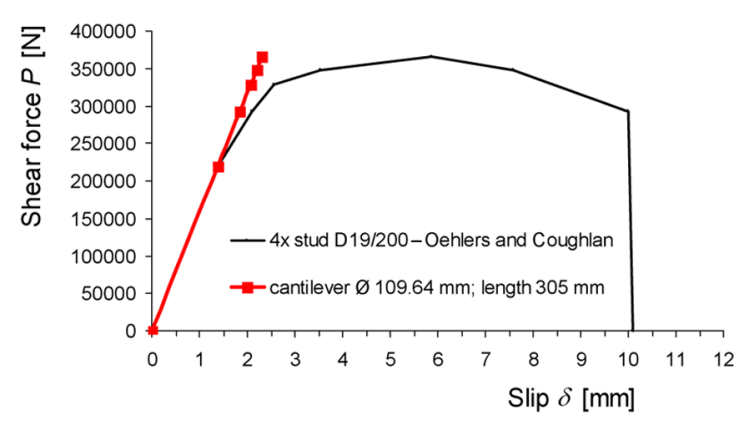

Fig. 7. Load-slip behaviour of 4 studs 19/200 [mm] and elastic linear modelling

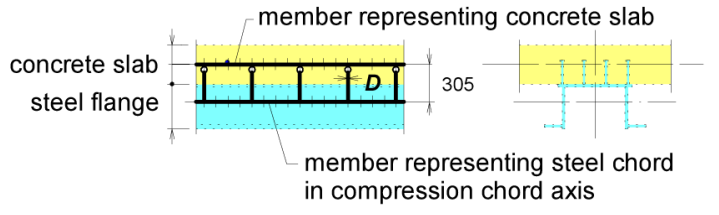

Fig. 8. 2D frame model of longitudinal shear connection

where: shear force $P$ and deflection $\delta$ correspond to Figure 7, length of the bar $\ell=305 \mathrm{~mm}$ and steel modulus of elasticity $E=210000 \mathrm{MPa}$. Resulting diameter $D=$ $109.64 \mathrm{~mm}$.

The four shear stud connectors $19 / 200$ [mm] with characteristic shear strength $4 \times 91.4=365.6 \mathrm{kN}$ (and spacing of $400 \mathrm{~mm}$ giving $914 \mathrm{~N} / \mathrm{mm}$ ) behaves fully linearly roughly up to $0.6 \times 365.6=219.4 \mathrm{kN}$.

Comparison of 3D MNA (ANSYS) and 2D LA (SCIA) results of longitudinal shear flow under loading of $200 \mathrm{kN} / \mathrm{m}$ (corresponding approximately to design bridge loading) together with Eurocode 4 (EN 1994-1-1 2004) approach is shown in Figure 9 (the detailed description of Eurocode solution was described elsewhere, see Machacek, Charvat 2013). The 2D LA reasonably and conservatively imitates the 3D MNA analysis, justifying its use for parametric studies of longitudinal shear. Eurocode approach seems to be very conservative.

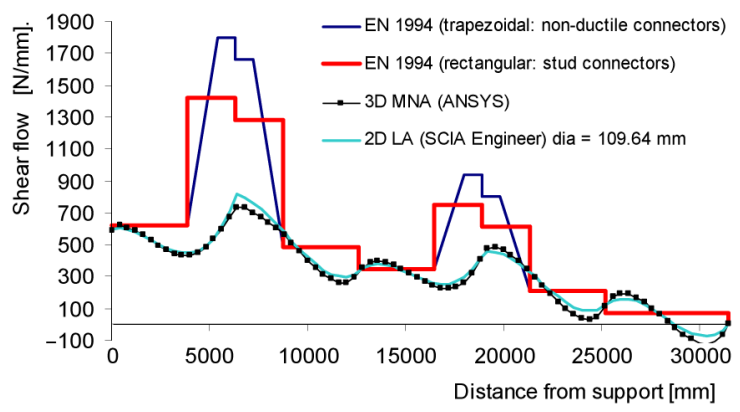

Fig. 9. Comparison of 3D MNA (ANSYS), 2D LA (SCIA) and Eurocode 4 (EN 1994-2 2005) distribution

\section{Parametrical studies}

Out of vast parametric studies performed for all the bridges in Figure 1 only results for the railway bridge shown in Figures 10, 11 are illustrated in the following.

Various bridge loadings in accordance with Eurocode 1 (EN 1991-2 2003) were employed and evaluated. However, the results shown in the following cover exclusively classified vertical design loading using LM71 model with appropriate coefficients (due to dynamic effects and eccentricity of railway track) for one truss girder as shown in Figure 12 and giving maximal longitudinal shear under consideration of an unpropped bridge construction and without supplemental dead loadings. Longitudinal shear due to the supplemental dead loading in the real bridge amounts to about $86 \%$ of the former (i.e. approx. $46 \%$ of the total design value) and is influenced by creep. As the creep is in the following investigated 


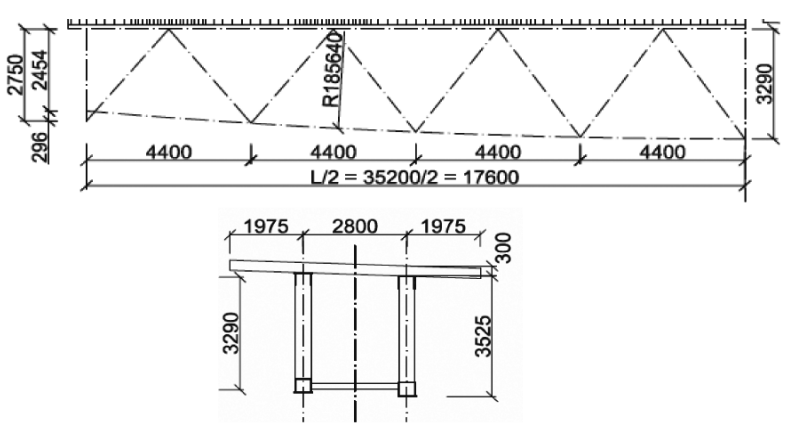

Fig. 10. The bridge geometry

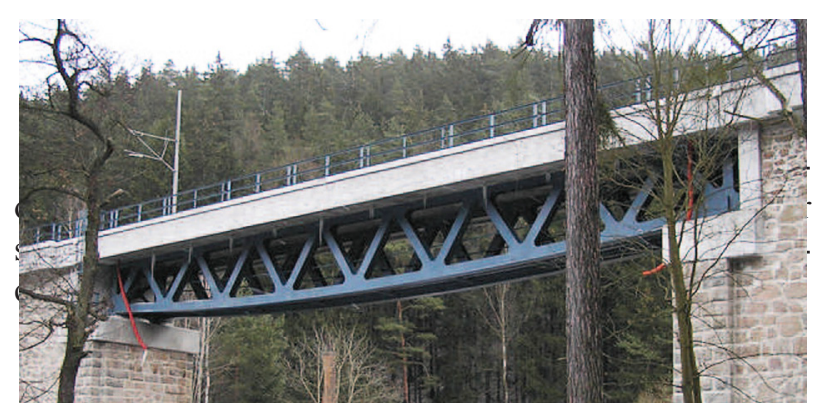

Fig. 11. Photo of the bridge

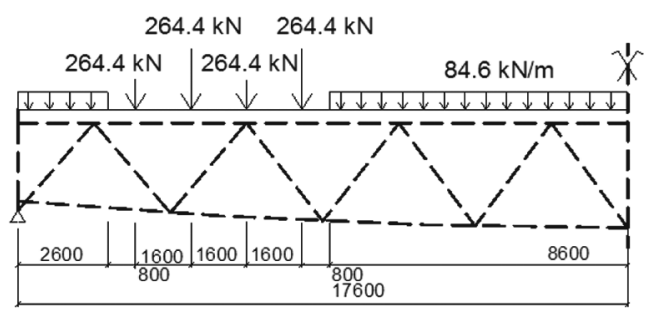

Fig. 12. Design bridge loading LM71 per girder

separately, the total shear values are not presented herein and for the real bridge in comparison to illustrated values are about twofold.

\subsection{Influence of rigidity of shear connection}

Rigidity of shear connection depends on number of shear connectors as obvious from Figure 13. In this study the welded studs $19 / 150[\mathrm{~mm}]$ in regular spacing of $200 \mathrm{~mm}$ with characteristic/design strength $P=81.6 / 65.3 \mathrm{kN}$ and various number $(1,5,10)$ placed in parallel position were considered.

The non-linear load-slip diagrams resulting from large set of push-out tests (Oehlers, Coughlan 1986) were again linearized with a fully elastic behaviour valid up to $60 \%$ of characteristic values. Cylindrical members modelling the connectors in accordance with Figure 8 were of $280 \mathrm{~mm}$ length with corresponding diameters $(72,108$, $128 \mathrm{~mm}$ ) and spacing of $200 \mathrm{~mm}$. First the total transmitted shear flow is shown in Figure 14, pointing to a significant increase of shear peaks above truss nodes due to increasing shear connection stiffness. Therefore, a simple proportional spreading of shear connectors to cover

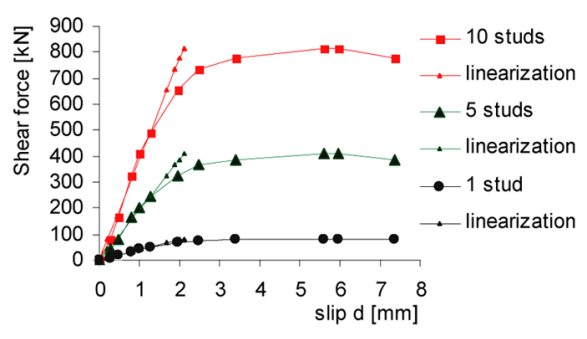

Fig. 13. Load-slip relationships of shear studs $19 / 150 \mathrm{~mm}$

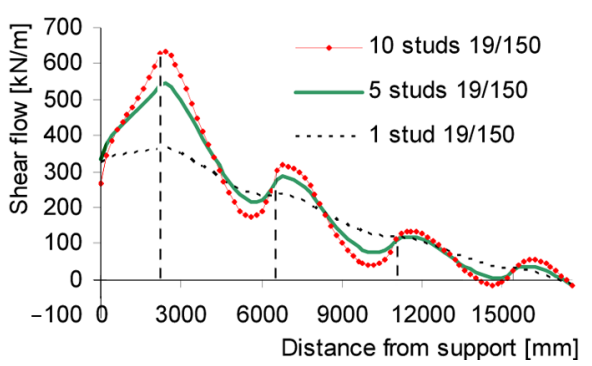

Fig. 14. Effect of the shear connection rigidity on shear flow

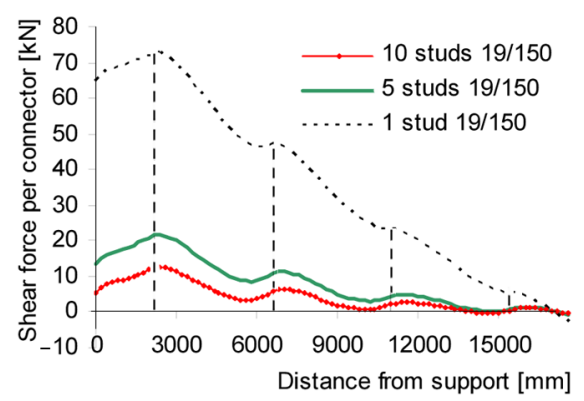

Fig. 15. Effect of the shear connection rigidity on shear per connector

any of the shear flows (i.e. using a simple corresponding number of shear connectors to cover the flow) is not correct and the final rigidity fitting to applied connection is substantial.

This is obvious from Figure 15. The proper values of shear forces per connector above the first truss node for $1,5,10$ connectors are 73,22 and $13[\mathrm{kN}]$ respectively. However, the simple spreading of the shear flow corresponding e.g. to one stud from Figure 14 leads to values approximately of 73,15 and $7[\mathrm{kN}]$, respectively.

\subsection{Influence of rigidity of steel truss chord}

Investigation of influence of both area and second moment of area of the steel truss chord was accomplished. In the studies three shear stud connectors $19 / 150[\mathrm{~mm}]$ in parallel position and spacing $200 \mathrm{~mm}$ were considered, using appropriate modelling by due cylindrical members.

Influence of chord area is presented in Figure 16, where the area from the former initial value $\left(A_{\mathrm{ch}}=33500 \mathrm{~mm}^{2}\right)$ was half or doubled $\left(16750 \mathrm{~mm}^{2}\right.$ or $67000 \mathrm{~mm}^{2}$, respectively) while the chord second moment of area remained the same $\left(I_{\mathrm{ch}}=4.9 \times 10^{8} \mathrm{~mm}^{4}\right)$. 


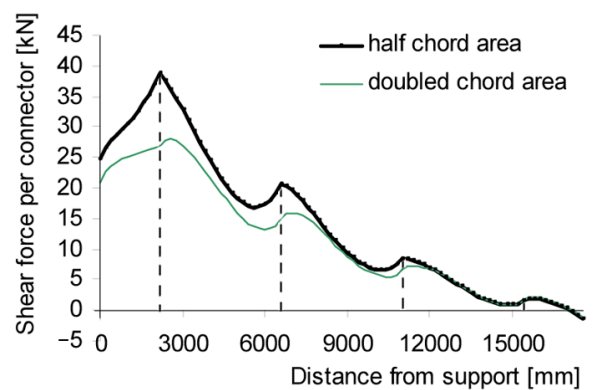

Fig. 16. Effect of the steel chord area

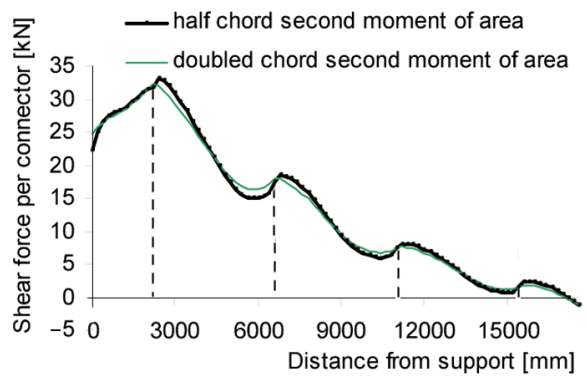

Fig. 17. Effect of the steel chord second moment of area

Similarly a study of the value of the chord second moment of area is shown in Figure 17, with half or doubled value $\left(2.45 \times 10^{8} \mathrm{~mm}^{4}\right.$ or $9.81 \times 10^{8} \mathrm{~mm}^{4}$, respectively) while keeping the same initial chord area $A_{\text {ch }}=33500 \mathrm{~mm}^{2}$.

The study demonstrates the principal significance of the steel truss chord area while the second moment area of the steel truss chord practically does not influence the distribution.

In a real bridge design the area and the second moment of area (chord rigidity) are tied together. Supplemental studies concerning extremely low and high rigidities (not presented here) proved the peaks of longitudinal shear above truss nodes increase rapidly with low (approaching to zero) rigidities.

\subsection{Influence of rigidity of concrete slab}

Values of the longitudinal shear strongly depend on amount of the mass (i.e. concrete slab) connected to the steel truss. The distribution of shear forces per connector is shown for half and doubled concrete slab area $(1687 \times 300[\mathrm{~mm}]$ and $6750 \times 300[\mathrm{~mm}]$, respectively $)$ in Figure 18. In the study three stud connectors in parallel position with $19 \mathrm{~mm}$ diameter and spacing in longitudinal direction of $200 \mathrm{~mm}$ were considered. While with the greater mass the shear clearly increases, the shear peaks above truss nodes are becoming less noticeable.

Another study concerned concrete slab aspect ratios. For the same shear connection and two different depth/ width ratios the results are shown in Figure 19. Aspect ratio of the slab (width/depth) seems not to be substantial for the longitudinal shear distribution.

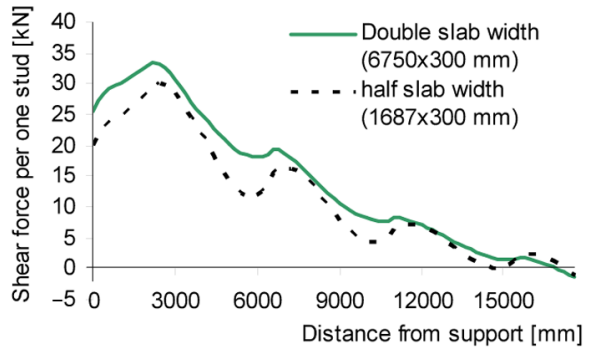

Fig. 18. Effect of concrete slab width

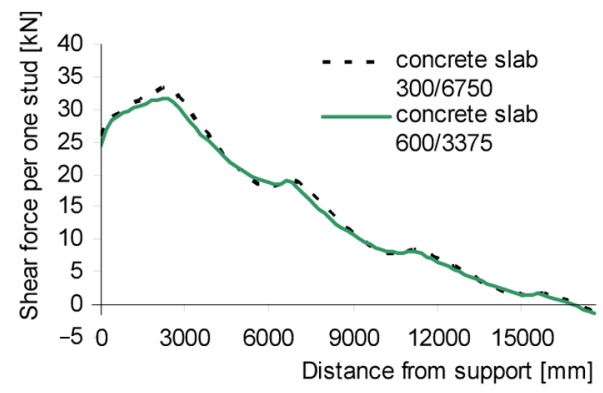

Fig. 19. Influence of concrete slab aspect ratio

Supplemental studies concerning influence of concrete slab dimensions on the longitudinal shear were performed, keeping the steel truss unchanged. Enormous dimensions of concrete slabs resulted into low shear values were the peaks disappeared while with minimal slabs the peaks were emphasized but also of very low total shear values.

\subsection{Concentration of shear connectors above truss nodes}

The concentration of shear connectors above truss nodes in the regions of high longitudinal shear peaks is common in a design practice. However, the concentration of shear connectors increases the connection rigidity and subsequently attracts more shear flow to the relevant regions (Machacek, Charvat 2013). The extents of these regions were studied in some detail in former studies (Machacek, Cudejko 2011). With usual steel truss chord dimensions (without regard to node gusset plates) the extent of densification within a quarter distances between the nodes (both sides) seems to be appropriate. Nevertheless, an optimal design requires an iteration process outlined further.

The suggested procedure accepts the above extent of the densification (quarter node distance round both node sides) and corresponds to loading according Figure 12. Starting pattern fit to uniform distribution of 3 parallel studs $19 / 150 \mathrm{~mm}$ at spacing of $200 \mathrm{~mm}$. Densification of shear connectors above node regions led to increasing number of studs at the same spacing (in 2D LA approach to increasing diameters of cylindrical members). The first densification resulted from ratio of maximum to average shear force per stud along the truss in the first and second node regions and led to approx. 7.3 and 4.1 parallel studs at $200 \mathrm{~mm}$ spacing respectively, Figure 20. 


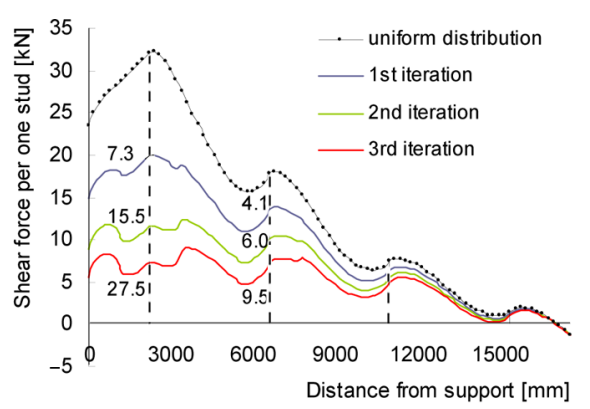

Fig. 20. Iteration procedure for optimal densification of studs

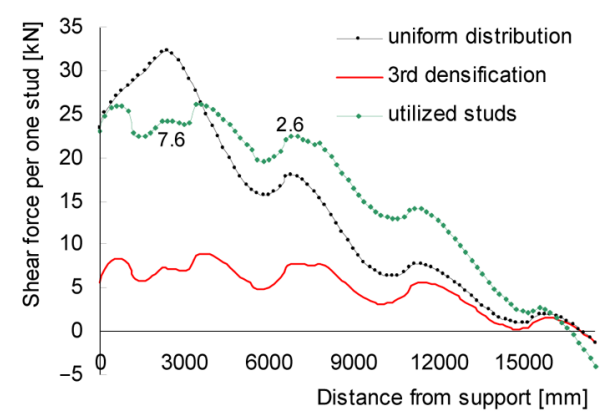

Fig. 21. Distribution for utilization of available stud capacity

The second densification followed the same rearrangement using average shear force per stud along the truss from the first densification and led to approx. 15.5 and 6.0 parallel studs at the first two nodes. Because of recurring increase of the shear flow above the nodes the third densification needed to be performed, leading to approx. 27.5 and 9.5 parallel studs at the first and second node respectively, keeping the $200 \mathrm{~mm}$ spacing.

With the iteration process and enlarging number of shear connectors the shear forces per connector obviously decrease. A linear magnification of the received shear forces to the shear stud capacity (here with respect to supplemental dead loading $\approx 0.54 \times 48.9=26.4 \mathrm{kN}$ ) may result in an appropriate utilization of the shear stud capacity along substantial truss length. In the investigated example the distribution resulted into 7.6 and 2.6 parallel studs above the first and second node (in $200 \mathrm{~mm}$ spacing), which corresponds to maximum shear force in the studs to $26.2 \mathrm{kN}$, see Figure 21.

The number of parallel studs and spacing in a real design must respect the relevant Standard (e.g. EN 1994-1-1 2004) limit values and other effects (temperature, shrinkage).

\subsection{Creep, temperature and shrinkage effects}

Creep effects on the longitudinal shear forces were studied for uniform supplemental dead loading of $94.05 \mathrm{kN} / \mathrm{m}$. The shear connection with 5 parallel studs $19 / 150$ [mm] in uniform spacing of $200 \mathrm{~mm}$ was introduced.

Modules of hardened concrete after 28 days, 2 months and 100 years were considered. The reduction of shear force per one stud is shown in Figure 22 together with total creep differential influence after 100 years.

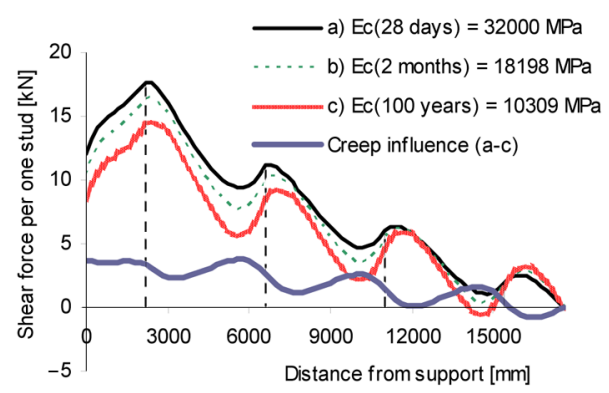

Fig. 22. Influence of concrete modulus of elasticity

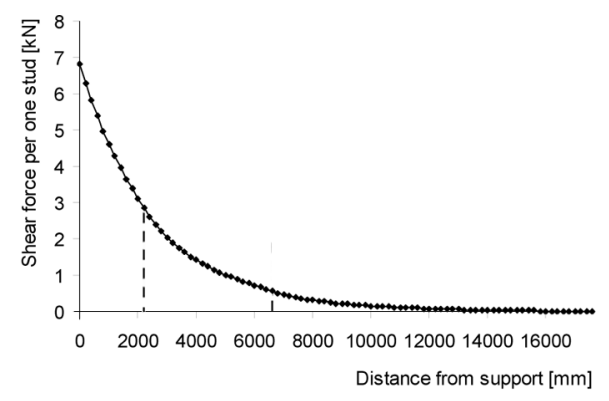

Fig. 23. Effect of temperature difference of $\pm 9^{\circ} \mathrm{C}$. Effects for 5 welded studs $19 / 150$ in $200 \mathrm{~mm}$ spacing

Temperature effects were investigated only for temperature difference between concrete and steel parts (simplified method according to Eurocode 1 (EN 1991-1-5 2003), with no non-uniform distribution of temperature). The design temperature difference in the studied bridge at load combinations in accordance with EN 1991-1-5 (2003) amounts to $\pm 9{ }^{\circ} \mathrm{C}$ (see Fig. 23). As obvious, the result roughly corresponds to the Eurocode 4 (EN 1994-1-1 2004) assumption of triangular distribution of longitudinal shear force due to temperature effects along the effective shear lag width for global analysis (where $b_{\text {eff }}=(0.55+0.2) \times 35.2 / 4=6.6 \mathrm{~m}$, while available $3.375 \mathrm{~m}$ ), with no peaks of the shear distribution above truss nodes.

Shrinkage effect on longitudinal shear corresponds to effect of concrete slab cooling. However, shrinkage is reduced by a creep. Distribution of shear forces due to shrinkage corresponding various times after the bridge assembly was also analyzed but not presented in this article.

\section{Conclusions}

The growing need for the proper design of shear connection in composite steel and concrete trusses emerges from the recent increasing number of composite truss bridges. While the full process of redistribution of longitudinal shear between a steel truss and a concrete slab from elastic to plastic stages is easily available through MNA (materially non-linear analysis) using sophisticated software, the elastic distribution is required in design of bridges, in case of rigid shear connectors with respect to their limited deformation capacity and for class 3 or 4 cross sec- 
tions (determined according to Eurocode 4 (EN 1994-1-1 2004)).

To avoid use of the complex and demanding software, the simplified 2D LA model suitable for both practical design and parametric studies concerning longitudinal shear distribution in composite steel and concrete bridges was suggested in the article. The proposed numerical model was verified with more complex 3D MNA and experimental results with reasonable agreement. The comparisons also refer to enormous conservatism of Eurocode 4 (EN 1994-1-1 2004) approach which is based on formulas for distribution of the longitudinal shear between the steel truss and a concrete slab resulting from local effects of a concentrated longitudinal shear force. Nevertheless, the Eurocode 4 (EN 1994-1-1 2004) approach may give the first guess about the shear peaks above the truss nodes.

The presented parametrical studies resulted into following conclusions with practical meaning:

1. The employed shear connection needs to be well described concerning load-slip relationship as the rigidity of the connection plays decisive role. The relationships for various shear connectors are readily available, e.g. in case of welded headed studs (Oehlers, Coughlan 1986) or perforated shear connector (Machacek, Studnicka 2002).

2. Linearization of the load-slip relationship for elastic analysis is usually correct up to roughly $60 \%$ of the characteristic strength connector value, which enable its use for a design with slightly conservative results.

3. High stiffness of the shear connection (either uniformly distributed or more concentrated above truss nodes) emphasizes peaks of the shear flow above truss nodes. A simple proportional spreading of shear connectors to cover shear flows resulting from another rigidity (i.e. using a simple corresponding number of shear connectors to cover the flow) is not correct and the final rigidity fitting to applied connection is substantial.

4. The peaks of the longitudinal shear distribution are more distinct for a greater area of the steel chord (therefore the area of gusset plates in node region is important). On the other side the peaks are little effected by the chord second moment of the steel chord area.

5. Concrete slab dimensions influence primarily the values of the shear flow, while the peaks of longitudinal shear rather increase with smaller dimensions.

6. Concentration of shear connectors above truss nodes as usual in design practice requires an iterative procedure. Suitable densification is suggested along a chosen length (depending on existence of node gusset plates) and the procedure is shown for a practical example.

7. Contrary to former effects the creep seems to be more pronounced in regions between the truss nodes. Using the 2D LA the creep may easily be analysed.
8. Temperature and shrinkage modified by creep have very similar effects on the longitudinal shear and forces in shear connectors as the ones in common plated composite steel and concrete bridges. Roughly triangular distribution of the longitudinal shear at the truss ends seems to be adequate with no shear peaks above truss nodes.

\section{Acknowledgements}

The relevant laboratory works were performed at the Central laboratory of Faculty of Civil Engineering of CTU in Prague. Thanks are due to local technicians and technical managers.

Support of the Czech Grant Agency GACR, grant No. 103/13/25781S, is gratefully acknowledged.

\section{References}

EN 1991-1-5 Eurocode 1: Actions on structures - Part 1-5: General actions - Thermal actions [Authority: The European Union Per Regulation 305/2011, Directive 98/34/EC, Directive 2004/18/EC]. European Committee for Standardization. Brussels, 2003. 49 p.

EN 1991-2 Eurocode 1: Actions on structures - Part 2: Traffic loads on bridges [Authority: The European Union Per Regulation 305/2011, Directive 98/34/EC, Directive 2004/18/EC]. European Committee for Standardization. Brussels, 2003. 167 p.

EN 1994-1-1 Eurocode 4: Design of composite steel and concrete structures - Part 1-1: General rules and rules for buildings [Authority: The European Union Per Regulation 305/2011, Directive 98/34/EC, Directive 2004/18/EC]. European Committee for Standardization. Brussels, 2004. 121 p.

EN 1994-2 Eurocode 4: Design of composite steel and concrete structures - Part 2: General rules and rules for bridges [Authority: The European Union Per Regulation 305/2011, Directive 98/34/EC, Directive 2004/18/EC]. European Committee for Standardization. Brussels, 2005. 93 p.

Bouchair, A.; Bujnak, J.; Duratna, P. 2012. Connection in steelconcrete composite truss, Procedia Engineering 40: 96101. http://dx.doi.org/10.1016/j.proeng.2012.07.062

Bujnak, J.; Duratna, P.; Bouchair, A. 2013. Behaviour of steelconcrete composite truss beams, in The Eight International Conference "Bridges in Danube Basin", 4-5 October 2013, Timisoara, Romania, 279-286.

Faggiano, B.; Marzo, A.; Mazzolani, F. M.; Calado, L. M. 2009. Analysis of rectangular-shaped collar connectors for composite timber-steel-concrete floors: Push-out tests, Journal of Civil Engineering and Management 15(1): 47-58. http://dx.doi.org/10.3846/1392-3730.2009.15.47-58

Johnson, R. P. 1997. Shear connection for composite bridges and Eurocode 4: Part 2, in Proceedings of Conference on Composite Construction - Conventional and Innovative, 16-18 September 1997, Innsbruck, Austria, 573-578.

Johnson, R. P.; Ivanov, R. I. 2001. Local effects of concentrated longitudinal shear in composite bridge beams, The Structural Engineer 79(5): 19-23.

Jung, K. H.; Yi, J. W.; Kim, J. H. J. 2010. Structural safety and serviceability evaluations of prestressed concrete hybrid bridge girders with corrugated or steel truss web members, Engineering Structures 32: 3866-3878. http://dx.doi.org/10.1016/j.engstruct.2010.08.029

Kravanja, S.; Silih, S. 2003. Optimization based comparison between composite I beams and composite trusses, Journal of Construction Steel Research 59(5): 609-625. http://dx.doi.org/10.1016/S0143-974X(02)00045-7 
Leon, R. T. 2005. Recent developments in composite construction in the USA, Advances in Structural Engineering 8(3): 259-274. http://dx.doi.org/10.1260/1369433054349114

Machacek, J.; Studnicka, J. 2002. Perforated shear connectors, Steel \& Composite Structures 2(1): 51-66. http://dx.doi.org/10.12989/scs.2002.2.1.051

Machacek, J.; Cudejko, M. 2009. Longitudinal shear in composite steel and concrete trusses, Engineering Structures 31(6): 1313-1320. http://dx.doi.org/10.1016/j.engstruct.2008.07.009

Machacek, J.; Cudejko, M. 2011. Composite steel and concrete bridge trusses, Engineering Structures 33(6): 3136-3142. http://dx.doi.org/10.1016/j.engstruct.2011.08.017

Machacek, J.; Charvat, M. 2013. Design of shear connection between steel truss and concrete slab, Procedia Engineering 57: 722-729. http://dx.doi.org/10.1016/j.proeng.2013.04.091

Marcinkowski, Z.; Berkowski, P. 1997. Experimental verification of bearing capacity of composite truss girders, in Proceedings of Conference on Composite Construction Conventional and Innovative, 16-18 September 1997, Innsbruck, Austria, 289-294.

Mirza, O.; Uy, B. 2010. Effects of the combination of axial and shear loading on the behaviour of headed stud steel anchors, Engineering Structures 32(1): 93-105.

http://dx.doi.org/10.1016/j.engstruct.2009.08.019
Mujagic, J. R. U.; Easterling, W. S.; Murray, T. M. 2010. Design and behaviour of light composite steel concrete trusses with drilled standoff screw shear connections, Journal of Construction Steel Research 66: 1483-1491. http://dx.doi.org/10.1016/j.jcsr.2010.06.001

Oehlers, D. J.; Coughlan, C. G. 1986. The shear stiffness of stud shear connections in composite beams, Journal of Construction Steel Research 6(2): 273-284. http://dx.doi.org/10.1016/0143-974X(86)90008-8

Skidmore, Owings, Merrill. 1992. Design of composite trusses. Publication 83, SCI, Ascot. 61 p.

Stadler, C.; Mayrhofer, G. 2010. An integral steel-concrete composite structure over a motorway in Austria, SEI 2010 20: 174-176.

Szmigiera, E. 2007. Influence of concrete and fibre concrete on the load-carrying capacity and deformability of composite steel-concrete columns, Journal of Civil Engineering and Management 13(1): 55-61.

Viest, I. M.; Colaco, J. P.; Furlong, R. W.; Griffis, L. G.; Leon, R. T.; Wyllie, L. A. 1997. Composite construction design for buildings. McGraw-Hill. 496 p.

Yatim, Md. Y.; Shanmugam, N. E.; Badaruzzaman, W. 2013. Behaviour of composite plate girders with partial interaction, Journal of Civil Engineering and Management 19(Suppl. 1): S1-S13.

http://dx.doi.org/10.3846/13923730.2013.801898

Josef MACHACEK. Professor at Faculty of Civil Engineering of the Czech Technical University in Prague (Czech Republic). He published more than 300 research papers and teaching books on stability and elastic-plastic strength of thin steel plates, progressive thin-walled steel and stainless steel elements, composite steel and concrete structures and textile membranes cooperating with steel structures (see http://people.fsv.cvut.cz/ machacek/).

Martin CHARVAT. PhD student under supervision of Professor Machacek. He graduated from Faculty of Civil Engineering of the Czech Technical University in Prague and intends to submit $\mathrm{PhD}$ thesis on longitudinal shear in composite steel and concrete bridges. 